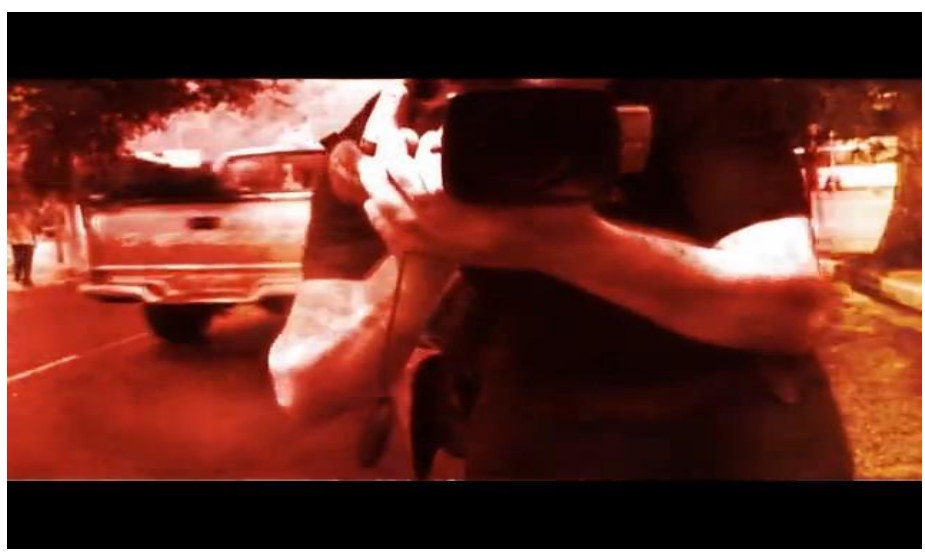

\title{
Recortes e(m) análise: no movimento da narratividade cinematográfica ${ }^{1}$
}

Cut outs and/under analysis: in the movement of narrative cinematographic.

\author{
Atilio Catosso Salles ${ }^{2}$ \\ Greciely Cristina Costa ${ }^{3}$
}

\section{Resumo:}

Como objetivo, numa posição discursiva, a partir do funcionamento do que temos chamado de uma política do olhar ideológico (XAVIER, 1977), busca-se compreender como se dão os efeitos de narratividade na base material da imagem. O corpus é constituído por recortes de imagens do documentário Território Vermelho de Kiko Goifman (2004) e, é, a partir do movimento destas imagens/recortes, na torção delas, pelo efeito de edição, que traçamos apontamentos sobre o modo como a cidade é discursivizada em uma narrativa fílmica. Neste jogo entre os efeitos da montagem e a cidade, temos os deslizamentos de sentidos que abrem o 'sinal' do semáforo para sujeitos $\mathrm{da} /$ na cidade se significarem em um território de existência, por seus diferentes modos, seja pelo lugar do silêncio e seus efeitos, ainda que aparentemente excluídos, sujeitos estão a significar, reclamando interpretação.

Palavras-chave: Análise de Discurso; Imagem; Território Vermelho; Sujeito; Narratividade.

\begin{abstract}
:
As objective, a discursive position, from the operation of which we have called for a policy of ideological gaze (Xavier, 1977), seeks to understand how the effects of narration in the material base of the image. The corpus consists of excerpts of images of the documentary Territorio Vermelho, Kiko Goifman (2004), and is, from the movement of these images/clippings, in torsion of them, by the effect of edition, which do we draw notes about how the city is discursivation in a filmic narrative. This game between the effects of the assembly and the city, we landslides of senses that open the 'signal' semaphore for subjects of/in the city if mean in a territory of existence, by their different modes, either by place of silence and its effects, although seemingly excluded, subject are the mean, complaining interpretation.
\end{abstract}

Keywords: Discourse Analysis; Image; Território Vermelho; Subject; narration

\footnotetext{
${ }^{1}$ Este artigo resulta da dissertação de Mestrado intitulada DISCURSO E IMAGEM: NARRATIVIDADE CINEMATOGRÁFICA NA/DA TRAVESSIA, defendida na Univás por Atilio Catosso Sales sob orientação da Profa. Dra. Greciely Costa.

${ }^{2} \mathrm{O}$ autor é doutorando em Ciências da Linguagem pela Universidade do Vale do Sapucaí (Univás). Av. Pref. Tuany Toledo, 470 - 37550-000 - Pouso Alegre - MG. E-mail: atiliocs@ gmail.com

${ }^{3}$ A coautora é Docente do Programa de Pós-Graduação em Ciências da Linguagem da UNIVÁS. Av. Pref. Tuany Toledo, 470 - 37550-000 - Pouso Alegre - MG. E-mail: greciely@ gmail.com
} 
Neste artigo buscamos compreender os processos de significação do documentário Território Vermelho $(2004)^{4}$. A questão primeira que se impôs foi: sujeitos ao espaço da cidade nos significamos ao nos filiarmos a um território (ROLNIK, 1997)? Este compreendido enquanto lugar de pertencimento pelo próprio de nossa existência, não como mero espaço físico com suas divisas geográficas. Acontecimento de duas ordens, pensamos: do sujeito do discurso no espaço 'congestionado' da cidade e o próprio acontecimento de um material que flagra o sujeito e seu percurso.

Como material de leitura recortamos um documentário, Território Vermelho (2004), produzido por Kiko Goifman. Um semáforo e sujeitos que são 'salvos' pelas câmeras de vigilância. Sujeitos flagrados que percorrem o Território com câmeras e, num gesto duplo, são flagrados pelas câmeras ao mesmo tempo em que tentam capturar em imagem o Território. Flagrantes com espessura semântica que desliza por sentidos de existência.

O gesto de recortar as 'imagens' em Território Vermelho para a composição de nosso corpus é de alguma maneira tomar uma posição frente ao modo como a cidade se diz: ao sobrepor, recortar limites estamos chamando atenção para como a cidade em dizeres sobre a cidade, textualiza um enquadramento do espaço, produzindo um amontoado de interpretações.

Os espaços da cidade formulam trajetos, cruzam, entrecortam relações entre sujeitos, trazem em suas matérias tensões entre morar e passar, entre ir e ficar, entre resistir e insistir.

O urbano na relação com o funcionamento discursivo de nosso corpus nos aponta que a cidade re-interpreta seus espaços a todo momento; espaços que ficam entremeados com outros: moradia, sobre-vivência, trabalho. Cidade pensada como texto. Documentário pensado como texto que "representa imaginariamente o dizer como uma extensão com limites, pausas, beiradas (bordas) possíveis" (ORLANDI, 2001c: 93), possíveis pois sabemos que sempre podem ser outras. E são outras: o sujeito em

\footnotetext{
4 Ao recortar um objeto de leitura em Análise de Discurso sabemos do caráter singular que o pesquisador imprime ao objeto: do recorte do material discursivo à inserção dos enunciados em determinada série de filiações sócio-históricas face às suas inquietações teórico-analíticas. O gesto de análise de cada pesquisador assim se constitui e se move. Dizemos isso, pois há outros trabalhos sobre Território Vermelho, mas cada análise é singular. Da perspectiva discursiva, é importante destacar o trabalho da pesquisadora Suzy Lagazzi (2012), intitulado: "O discurso em diferentes territórios: o vermelho entre todas as cores". A autora em sua leitura discursiva de Território Vermelho analisa a relação entre motoristas e abordadores no semáforo; ela ressalta que há uma impossibilidade de escuta, uma barreira que é da ordem do discurso, do simbólico, que se tece na história
} 
movimento ressignifica, se ressignifica ao percorrer o espaço com seu corpo, seu nome. São percursos que dizem sobre o sujeito, na medida em que eles se dizem na cidade.

A fala do sujeito que protagoniza Território, seu percurso em imagens mostradas e não-mostradas em fragmentos que recortam a cidade, e diremos, produz - no sentido de uma prática - eixos de uma discursividade que se formula em torno da diferença, da repetição, por uma sociedade cujo modo de produção é capitalista. Com contornos e ‘torções' específicas entra em cena a palavra resistência (pensada não somente como "estar contra x" ou "fora de x"). Lembramos aqui a imagem de Roland Barthes: assim como o poder, o quotidiano é como uma água que escorre por toda parte. Resistência que remete à questão da identificação no funcionamento próprio da ideologia que fal(h)a ao sujeito. Ideologia esta que não é consciente, mas "um efeito da relação do sujeito com a língua e com a história na sua necessidade conjunta, na sua materialidade" (ORLANDI, 1996, p.112). Nessa direção, questionamos: sujeitos de Território que contrariam o quê?

O que nos resta? A busca por um território de filiação (?). Espaço para repetir. Repetir até ficar diferente (Manoel de Barros, 1993). A ordenação do espaço, pensamos, não pode estar separada da ordenação do sujeito. Compreender os processos de significação do documentário Território Vermelho nesse espaço citadino de várias inscrições simbólicas, onde este fora gravado/produzido, nos permite retraçar o percurso de sentidos, sentidos e seus efeitos em funcionamento na tela.

A textualização das imagens em Território Vermelho aponta para um complexo de sobreposições de diferentes materiais em processo de significação, faz acionar uma rede de memória do/sobre o urbano, marcado por divisões, disjunções, retomadas, deslocamentos... para além da dimensão do representável e visível.

Aqui, retomamos alguns trechos do documentário.

Território é dividido, picotado, recortado em seis narrativas que se entrecruzam. Há uma espécie de rachadura nas cenas que as separam. A tela é apagada, um som insistente começa a ser ouvido. Vários sentidos para câmera e nomes de pessoas acendem na tela, as letras são vazadas e no buraco dessas letras passam imagens vermelhas em movimento rápido.

Tensão. 
Recorte 01

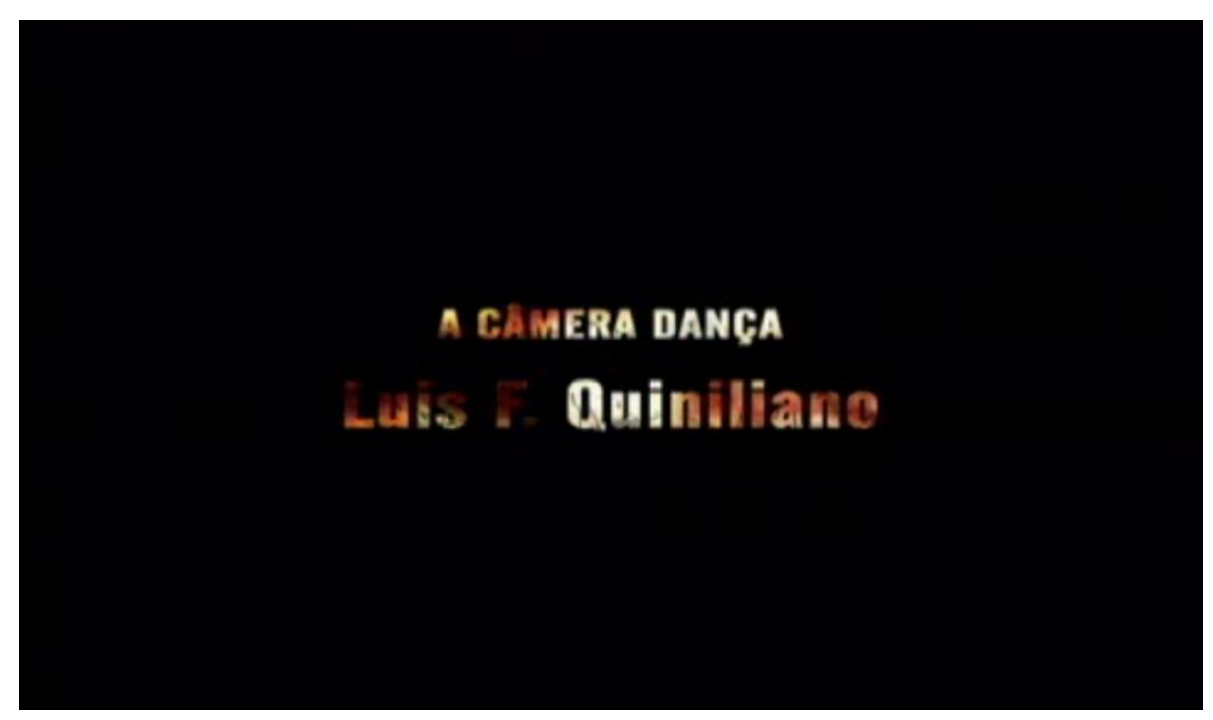

Recorte 02

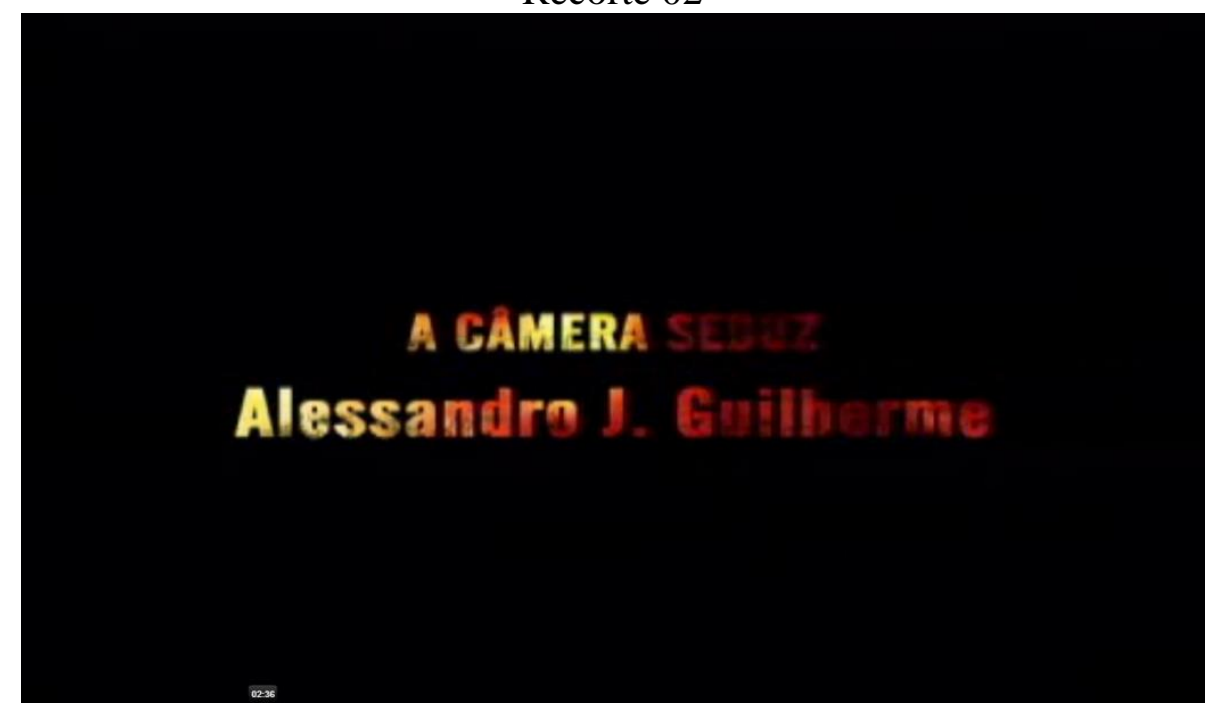

Recorte 03

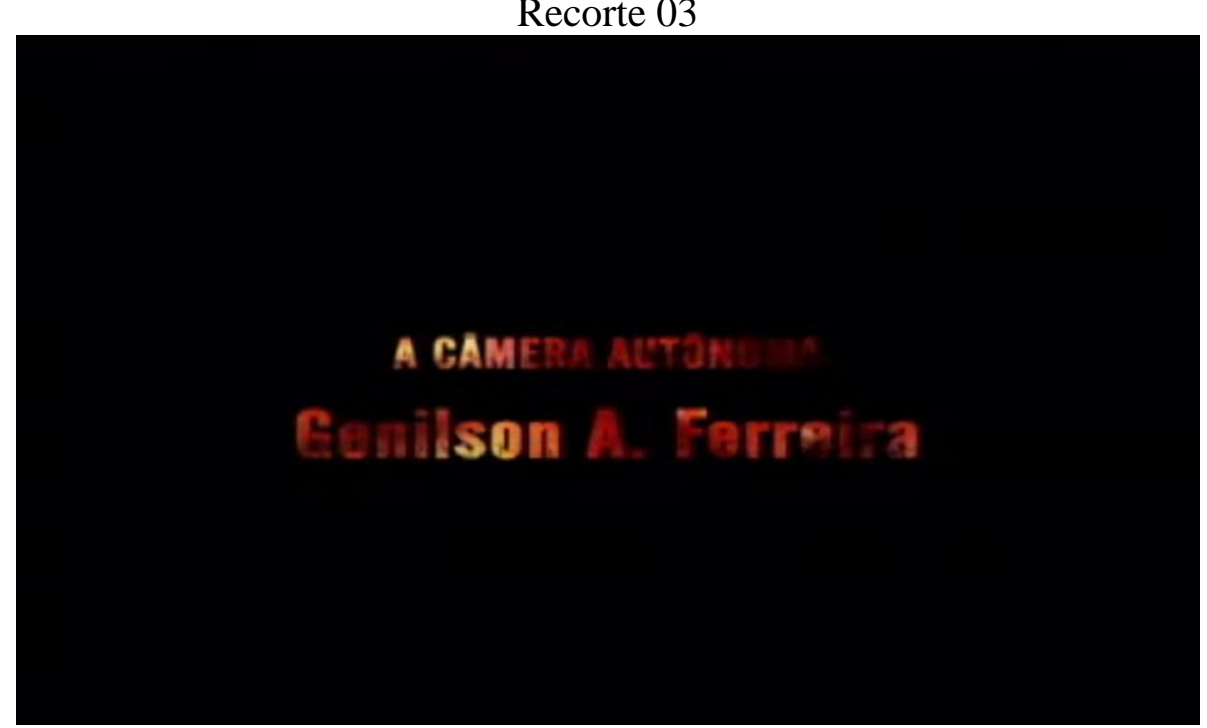


Recorte 04

\section{A CAMERA ROBA Evandro S. do Almoida}

Recorte 05

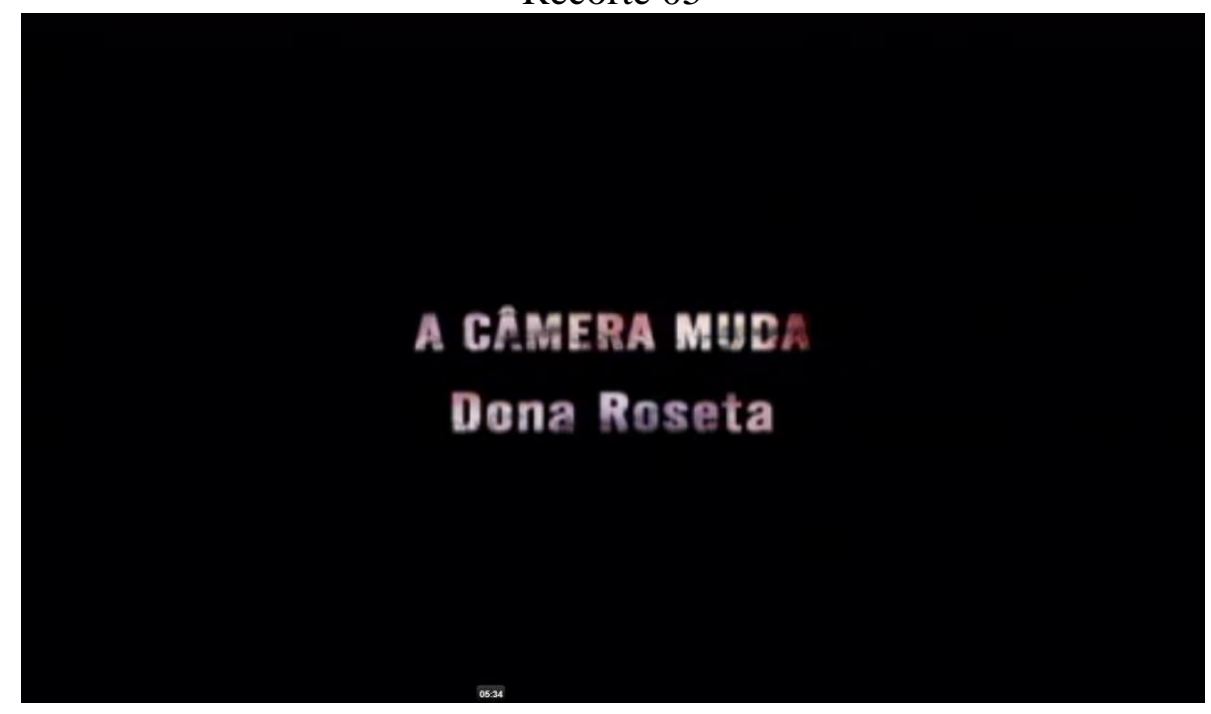

Recorte 06

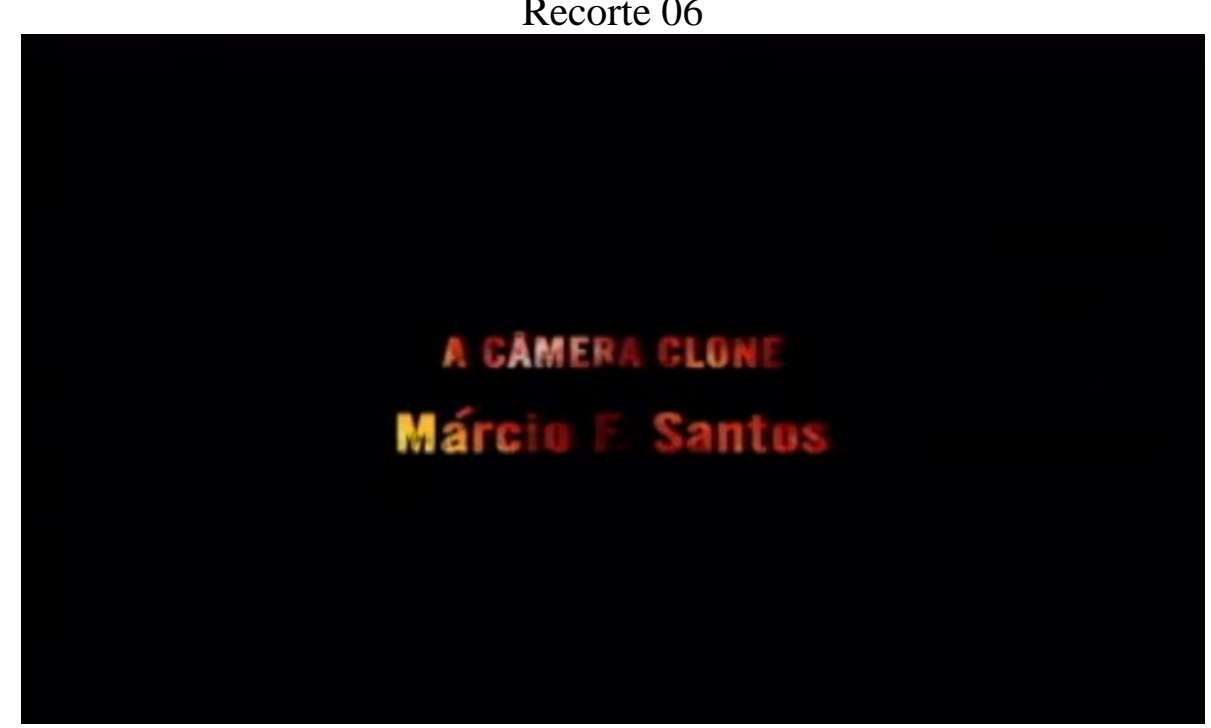


Diante das sequências discursivas apresentadas, num primeiro movimento de análise, apontamos para uma intensa fragmentação da forma-sujeito em Território, dada as diferentes posições-sujeito ocupadas numa mesma formação discursiva; a formação discursiva dos que sobre-vivem com o trabalho no semáforo. Esta possibilidade de fragmentação da forma-sujeito nos indica, de início, que o ritual discursivo não é capaz de engessar os sentidos, os sujeitos de Território se identificam, se contra-identificam, numa re-inscrição que não cessa, sem romper necessariamente com a formação discursiva a que se encontram filiados. É devido a esse funcionamento que se abre a possibilidade dos deslizes de sentidos no interior de um mesmo domínio do saber.

Vejamos por passeios um pouco desse funcionamento que estamos desejando formular.

Primeiro passeio (recorte 01) - A câmera dança - Luiz F. Quiniliano com o seu fone de ouvido lava para-brisas, 'vidros'; “Essa é a nova moda agora, limpar o vidro com a câmera na mão, doutor", ele insiste ao transitar por entre os carros e motocicletas.

Segundo passeio (recorte 02) - A câmera seduz - Alessandro J. Guilherme interpreta o personagem 'gayparzinho' (o fantasminha camarada), adaptado por ele mesmo.

Terceiro passeio (recorte 03) - A câmera autônoma - Genilson A. Ferreira trabalha como autônomo desde os cinco anos de idade vendendo 'pano de prato', 'saco alvejado' (?) e 'bolsinhas'.

Quarto passeio (recorte 04) - A câmera muda - Dona Roseta vende canetas e durante seu percurso enuncia: "o país aqui é rico, olha aí, (ela aponta para os arranha-céus da cidade de São Paulo), o país é rico, é pobre? Não é uma vergonha? Quê que você acha disso aí?".

Quinto passeio (recorte 05) - A câmera roda - Evandro S. de Almeida é um cadeirante, jogador de basquete que "trabalha solicitando contribuições" para o seu time.

Sexto e último passeio (recorte 06) - A câmera clone - Márcio F. Santos se "fantaseia" de jornalista/repórter famosa, se "desfantasia" e, ainda, às vezes sai de "normal", de "hominho", pedindo contribuição para a sua companhia de teatro. A sua última palavra é 'sucesso'.

A nomeação de espaços urbanos, a produção de uma referência no espaço tem a ver de modo específico com a simbolização desse espaço: ou seja, o modo como um nome, um título (se) projeta (em) outros recortando uma memória. É nessa direção que 
nos interessa pensar os efeitos de sentido do nome próprio e do título em face da produção de saber sobre a cidade.

A compreensão das relações discursivas joga com a produção da ilusão de uma objetividade, de um referente, como se o sentido estivesse sempre já-la: como se os espaços entre os carros, entre as esquinas guardassem a interpretação de possíveis significações.

A construção discursiva dos referentes é de uma complexidade muito maior neste caso. Há um movimento entre o sujeito que diz e o que diz que constitui o sujeito quando ele filma. Uma dobra; de um sujeito em relação às próprias posições discursivas que o constitui. Sujeito que ocupa posição em uma formulação narrativa que o descreve, localiza, relata (justamente pela dificuldade que o discurso da urbanização tem em trabalhar com aquele que passa a ocupar o espaço planejado para ficar vazio).

Há um sujeito que filma e ao mesmo tempo é personagem: um duplo real do enquadramento. Nas telas recortadas pelos nomes próprios e títulos essa mesma dobra (ROLNIK, 1997) se tece, vejamos o recorte 05:

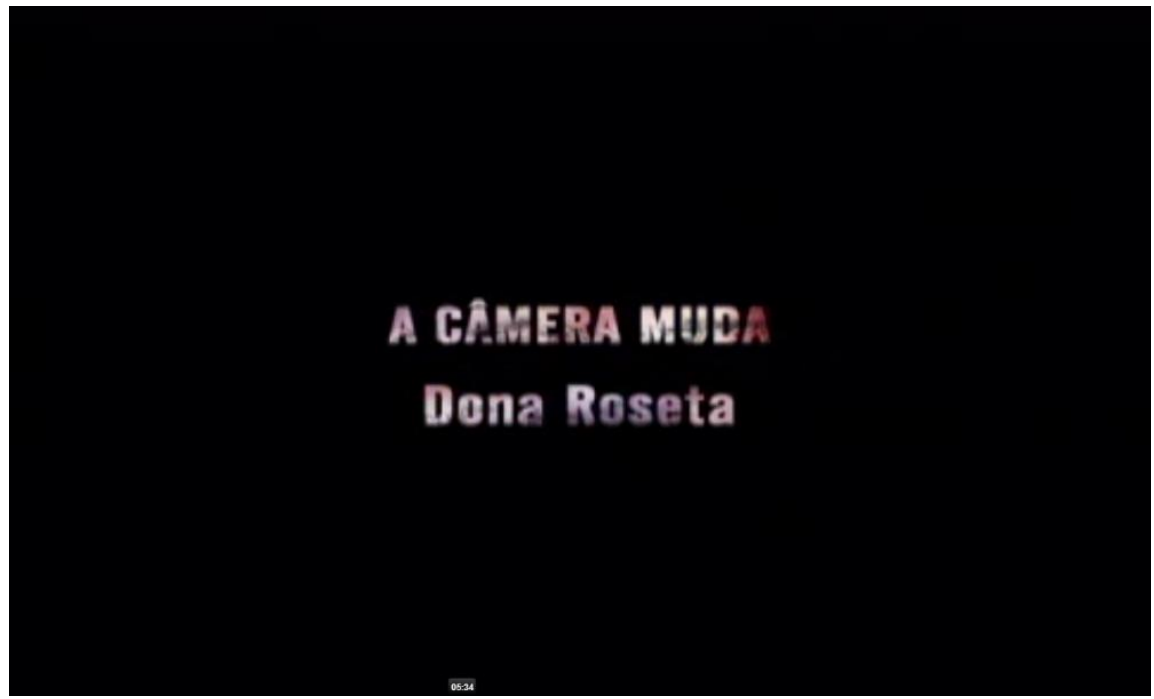

Abaixo do título "A câmera muda", aparece o autor, Dona Roseta, que desliza para o lugar de personagem também. O nome é do autor e do personagem que relata. A narratividade cinematográfica é, portanto, do nível da formulação dos sentidos. Narrar é se inscrever/escrever na linguagem, em sua materialidade; é o ponto de efeito da memória flagrada na tela que compõe o cenário: a cidade. Narrativa, boatos, versões. É o corpo do sujeito que pela narratividade cinematográfica cola ao corpo da cidade. 
O nome próprio produz uma referência que é a que está no enquadramento que vem do olho que o torna imagem. O nome é o que decide "ter tido-lugar". É uma forma narrativa, a câmera que enquadra.

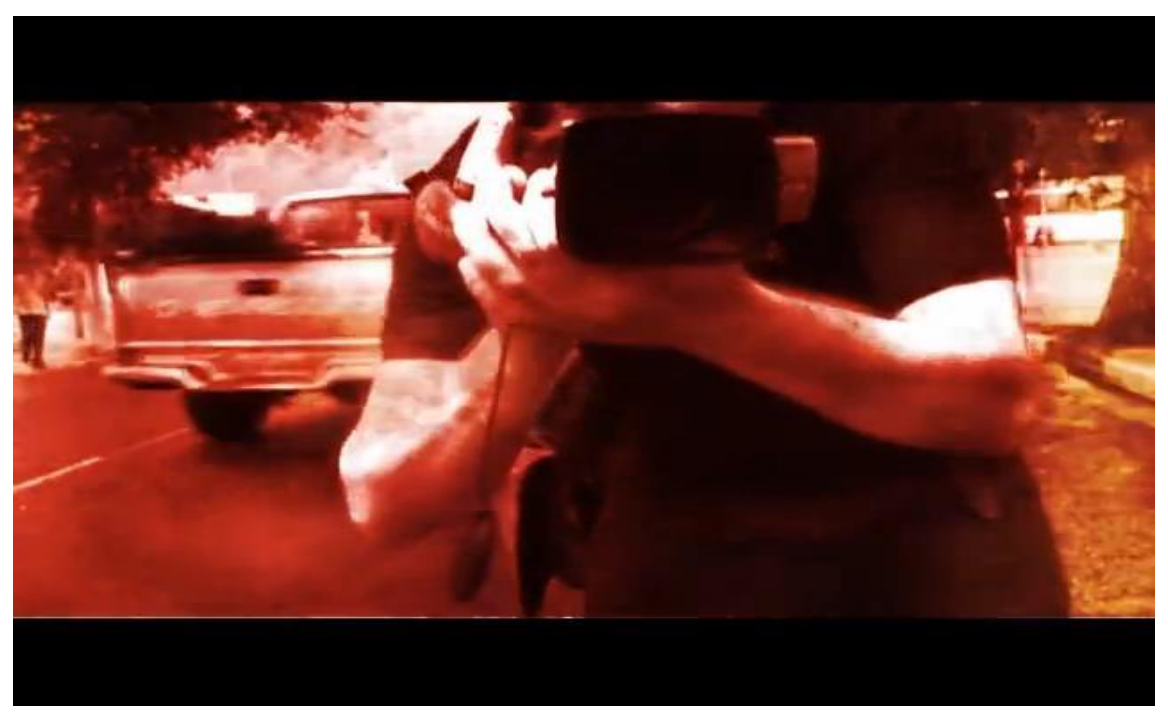

Câmera que enquadra ao dançar, ao seduzir, ao se constituir autônoma, ao mudar, ao rodar, ao ser clone...

Dessa forma, no que diz respeito ao funcionamento discursivo da referência, Pêcheux (2011), aponta:

A referência discursiva do objeto já é constituída em formações discursivas (técnicas, morais, políticas...) que combinam seus efeitos em efeitos de interdiscurso. Não haveria assim naturalidade "técnica" do balão livre ou da estrada de ferro, ou naturalidade "zoológica" da toupeira, que seria em seguida objeto de metáforas literárias ou políticas; a produção discursiva desses objetos "circularia" entre diferentes regiões discursivas, das quais nenhuma pode ser considerada originária.

Os nomes identificam os objetos em virtude de significá-los, enquanto que a referência, atravessada pelo simbólico, rediz o dito, aponta para outros dizeres na história. O nome próprio faz referência ao que está no enquadramento, ao passo que o título (a câmera + uma predicação) faz parte da narrativa a partir de uma formação discursiva, na qual se inscreve àquele que enquadra o sujeito. Lemos os títulos que vazam na tela de Território Vermelho (a câmera dança; a câmera seduz; a câmera autônoma; a câmera muda; a câmera roda; a câmera clone), retomando Pêcheux (1990, p.20), como sendo um gesto que vem: 
a prefigurar o acontecimento, a dar-lhe forma e figura, na esperança de apressar a sua vinda... ou impedi-la [...]. Mas esta novidade não tira a opacidade do acontecimento, inscrita no jogo oblíquo de suas denominações.

A inscrição de uma função autor (ORLANDI, 2001) na narratividade cinematográfica possibilita que esse sujeito se inscreva - real do enquadramento. Acontecimento antes da denominação (PÊCHEUX, 1990). Denominação compreendida como sendo a marca de entrada no processo discursivo de significação.

No trajeto de dizeres, na forma do título vazado, as formulações dos sujeitos de Território Vermelho são enunciadas numa relação de dobra, que se dá entre a câmera e o sujeito que filma e ao mesmo tempo é filmado, colocando o sujeito em cena, em pedacinhos, flagrados e flagrantes, como se observa:

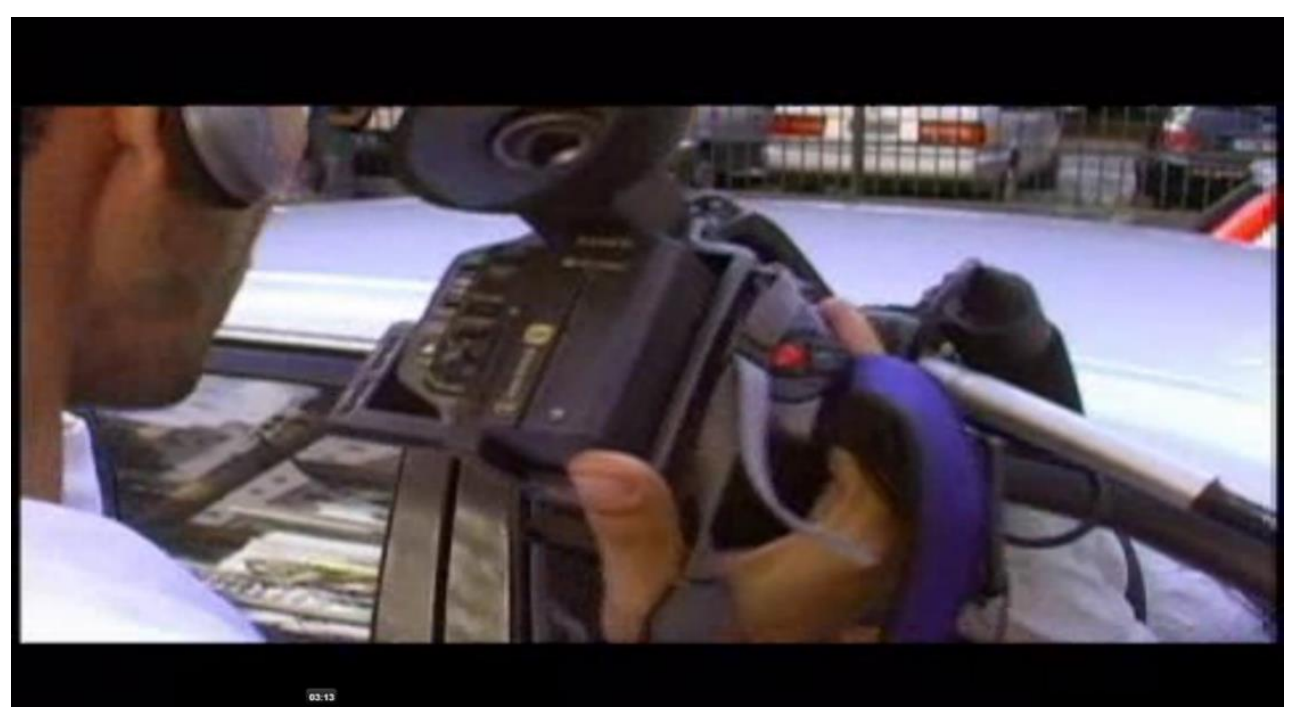

A partir ainda da sequência de imagens recortadas anteriormente, que introduz o passeio de cada sujeito pelo Território, é possível estabelecer paráfrases como:

Recorte 01 -

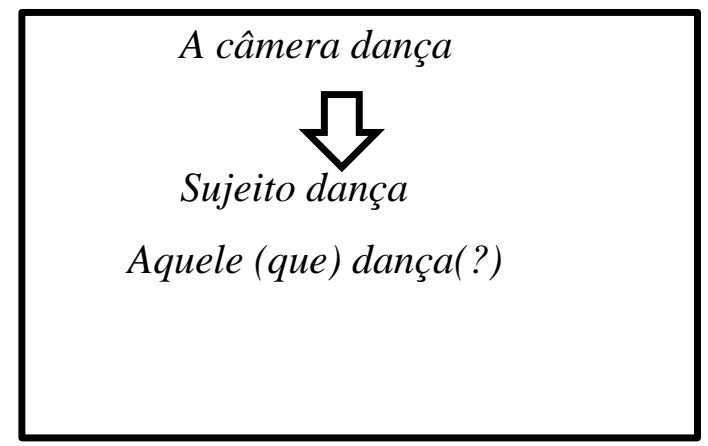


Recorte 02

A câmera seduz

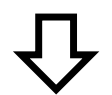

Sujeito seduz

Aquele (que) seduz

Recorte 03 -

A câmera autônoma

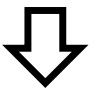

Sujeito autônomo

Aquele que é autônomo

Recorte 04 -

A câmera muda

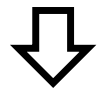

Aquele que muda

Sujeito mudo (?) 
Recorte 05

A câmera roda

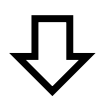

Aquele que roda (?)

Recorte 06

A câmera clone

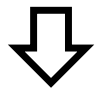

Aquele que é clone

Mariani (2005, p.144) propõe pensar que "a relação de identidade se estabelece pela repetição do nome [...]". Nessas telas congeladas, nomes próprios insistem e deslizam para o sentido de câmera. Ao passo que afirmar que existe assim uma relação que se enuncia entre a câmera e o sujeito, pois há certa predicação da câmera que tem a ver com a predicação do sujeito, pela prática dele no semáforo, é importante para compreendermos o processo de significação que se dá à medida que algo do sujeito ao significar é recortado para predicar a câmera.

A ambiguidade acima tecida entre os nomes (comum - câmera; e nome próprio os nomes dos personagens que protagonizam Território Vermelho) nos possibilita formular ${ }^{5}$ alguns lugares possíveis de deriva:

\section{“A câmera dança” - Luiz F. Quiniliano;}

\footnotetext{
${ }^{5}$ Ver em Pêcheux (2009), In. Articulação dos enunciados, implicação de propriedades, efeito de sustentação), em que o autor avança na compreensão de 'composição preposicional', ao apontar para o equívoco fundamental do idealismo lógico de Frege.
} 
Em que a interpretação 'determinativa' supõe uma relação subjacente do tipo: Luiz F. Quiniliano (sendo o homem que, ao som do rap, trabalha no semáforo) conduz a câmera que dança, dança também, o que corresponde à forma geral (onde "Nome próprio" designa e é designado pelo "Nome comum" (câmera)):

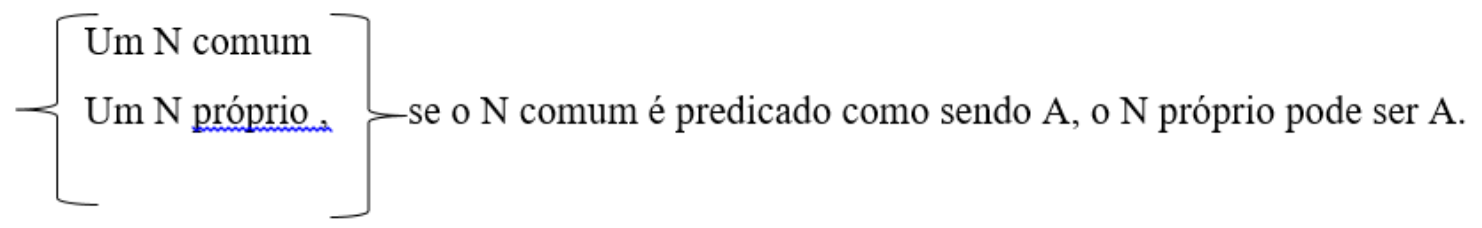

A identificação pela câmera ${ }^{6}$ (nome comum que nas telas aparece predicado como sendo a câmera que dança, a que seduz, a autônoma, a 'que' muda, a 'que' roda e a clone), em que o sujeito se reconhece, é também organizada pela relação com aquilo que o (re)apresenta na narrativa documentária. Um jogo de cumplicidade entre o sujeito que trabalha, atua, encena, sobre-vive deste território, a câmera (aparelho estético ideológico), e um outro (personagem oculto) que irrompe na tela do documentário algumas vezes. É aquele que flagra pela câmera dele o sujeito que 'protagoniza' Território Vermelho (sujeito este com a sua câmera também em mãos para salvar 'acontecimentos').

Ponto de encontro de uma atualidade e uma memória que nos permitem acessar o real do enquadramento pela irrupção de significantes inesperados inscritos na base material da imagem, no sujeito, em seu corpo. E a partir dessas irrupções de significantes que, conforme aponta Pêcheux (2009), o

[...] sentido é produzido no non-sens pelo deslizamento sem origem do significante, de onde a instauração do primado da metáfora sobre o sentido, mas é indispensável acrescentar imediatamente que esse deslizamento não desaparece sem deixar traços no sujeito-ego da "forma-sujeito" ideológica, identificada com a evidência de um sentido (p.277).

Retomando a análise de Pêcheux (1975), propusemos alguns deslizamentos metafóricos pela relação Título e Nome próprio apresentados nas telas que estamos recortando para análise.

\footnotetext{
${ }^{6}$ Uma espécie de encantamento pela câmera por parte dos sujeitos de Território, isso, observado, quando apontamos para como cada um se relaciona com esse objeto (a câmera), fazendo-a deslizar pelo traçado da faixa de pedestre, e pelo gesto de deslizar mesmo, capturando pela lente um território de existência d(eles).
} 
Recorte 01

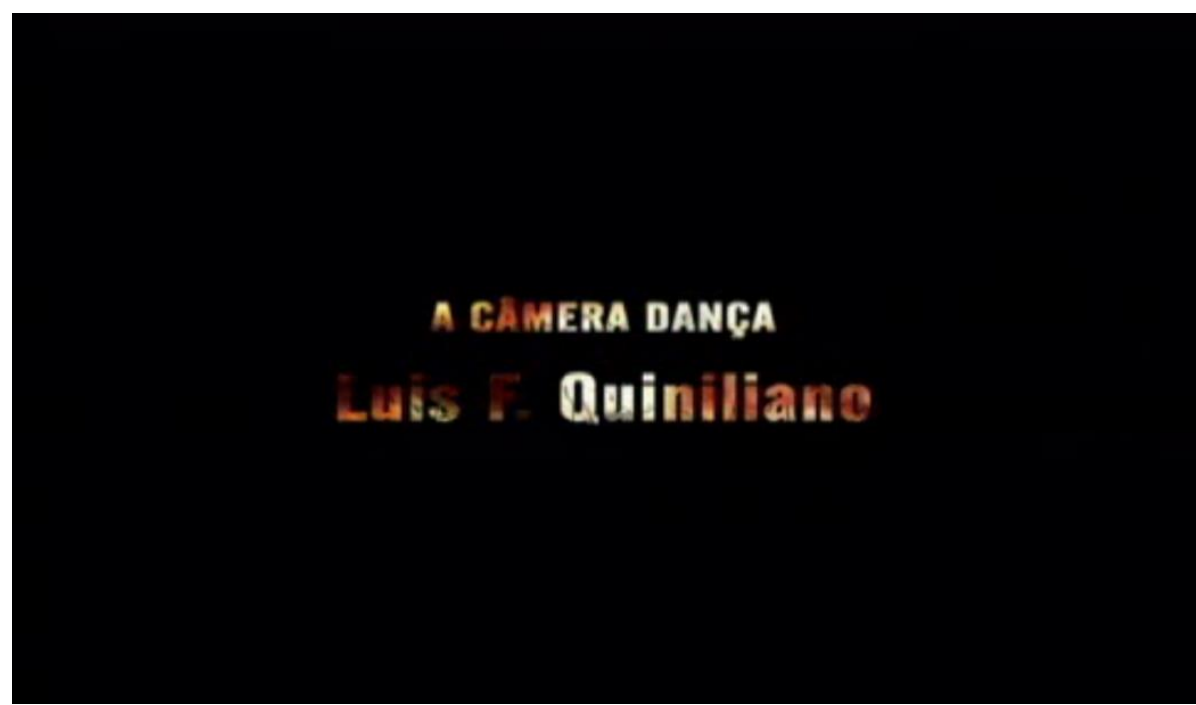

Implicadas na tela seguem os movimentos de sentido de relativas determinativas:

1. Luiz F. Quiniliano: aquele que dança e faz a câmera dançar ao som do 'rap'.

2. Alessandro J, Guilherme: aquele que com a câmera seduz pelo gesto da interpretação cênica.

3. Genilson A. Ferreiro: aquele que se diz como autônomo ao percorrer trajetos desde muito novo.

4. Dona Roseta: aquela que com a câmera muda ao resistir.

5. Evandro S. de Almeida: aquele que faz a câmera rodar.

6. Márcio F. Santos: aquele que com a câmera em mãos se fantasia e 'desfantasia'.

Aqueles que trabalham, atuam... em semáforos. A partir da construção dessas relativas determinativas do tipo: "aquele que.../ o que..." aponta para um "esvaziamento do objeto a partir da função" (p. 107), a determinação passa então a remeter ao indeterminado, "aquele que se torna equivalente a qualquer um que".

Aqueles que, qualquer um/todos. Paráfrases que em Território abre espaço para $o$ comum, aponta o lugar vazio, ao mesmo tempo, para o excesso de inscrições. Essa colagem do sujeito no espaço é deriva de uma forma de significação do próprio sujeito lutando por significações num espaço urbanizado. No fio da narratividade cinematográfica deslizam diferentes modos de nomeação dos sujeitos de Território, temos o malabarista, o vendedor de caneta, o limpador de para-brisa, atores... Não há como significar o sujeito que está na rua sem dizer o que ele faz/ou onde ele está.

Ao que parece, conseguimos avançar na compreensão de que "as palavras, expressões, proposições etc., mudam de sentido segundo as posições sustentadas por 
aqueles que as empregam" (PÊCHUX, 2009, p.146-147), no entanto, não significa que "lugares sociais" distintos assumam posições discursivas diferentes; observação esta própria do funcionamento da ideologia. Não estamos aqui querendo propor que as posições entre "os protagonistas de Território", a lei e a do próprio documentarista, por exemplo, estejam numa relação de simetria. Não. Afirmamos apenas que tais posiçõessujeito são sobredeterminadas pelo jurídico; sujeitos que são constituídos pela identificação com a condição de ser/estar cidadão responsável.

Em termos de constituição do sujeito, Orlandi (2007, p.48) afirma que: "o modo pelo qual ele se constitui em sujeito, ou seja, o modo pelo qual ele se constitui em posição não lhe é acessível'. Ligado a esta reflexão, propomos que em Território, os sujeitos estão investidos em um processo de constituição que nunca cessa ("um si e não si” em movimento que a todo o momento joga com "um sempre outro possível" na ordem da significação").

A vida tão 'vermelha' de sujeitos, quanto à do vermelho que dá nome ao documentário, atualiza por flashes, planos e enquadramentos tantos, no espaço do asfalto listrado de branco (faixa de pedestre), efeitos de sentido de um "dentro e fora" (do sujeito em relação ao 'seu' espaço). Não há separação. Temos corpos fletidos na faixa de pedestre que não se dissociam do Território. São pele e espaço sobrepostos materialmente.

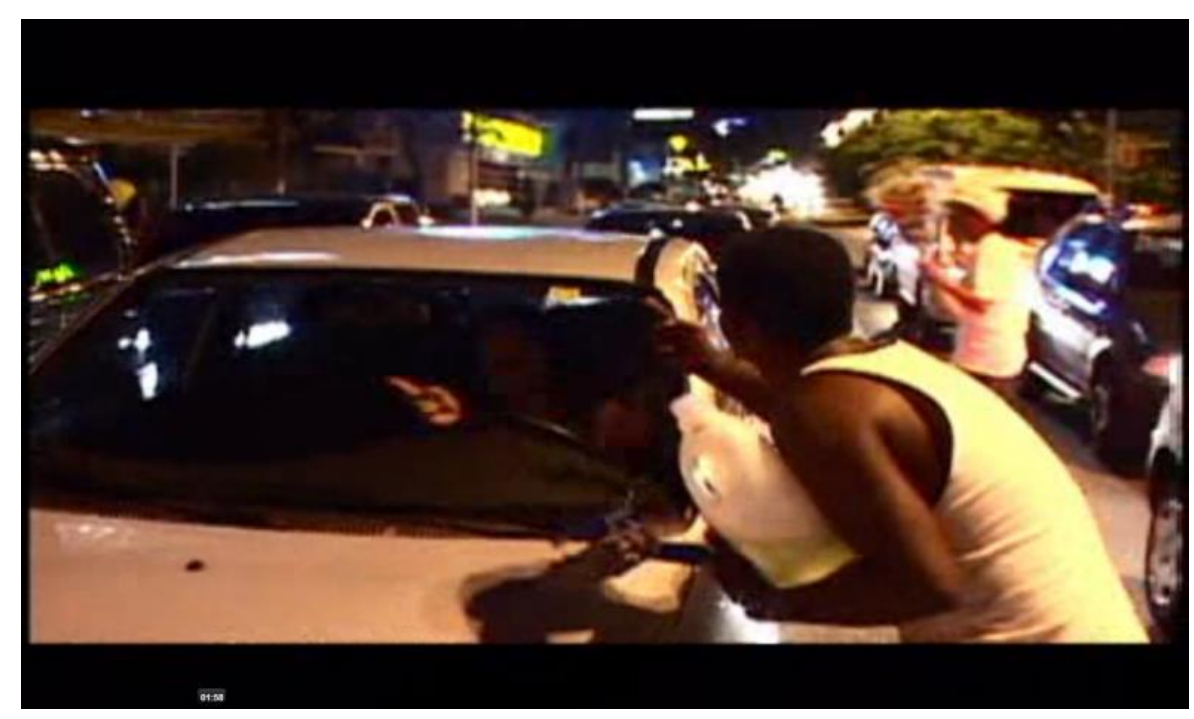



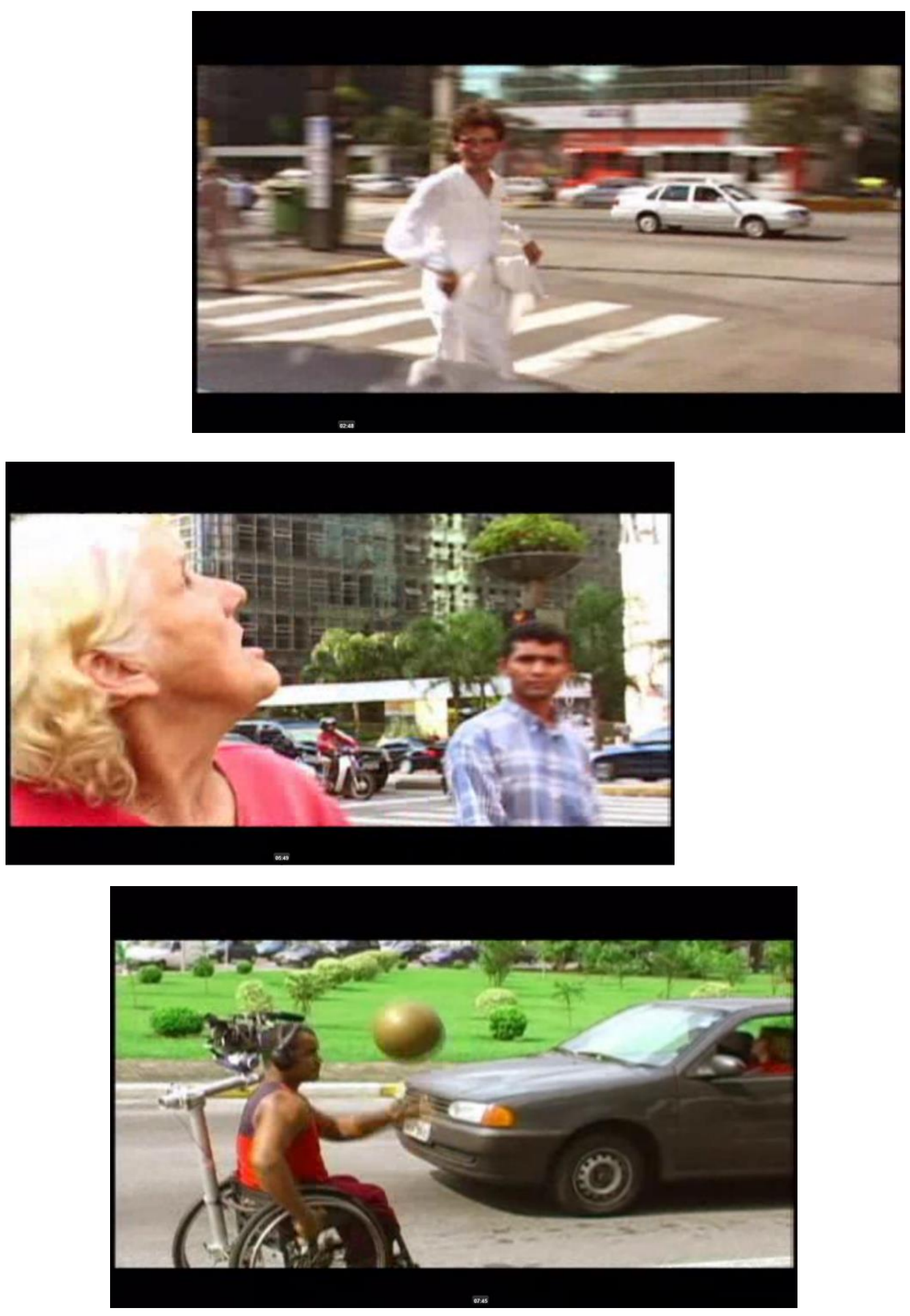


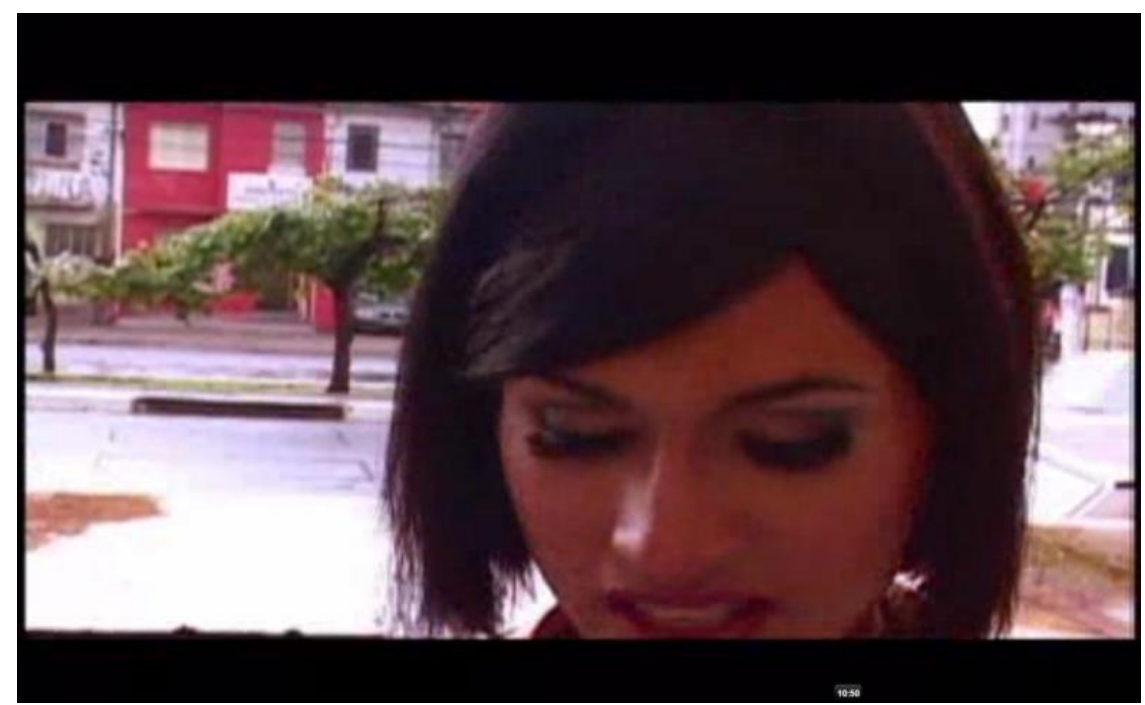

O corpo do sujeito vai se mostrando, sendo mostrado na imagem, atado ao corpo da cidade, ao corpo urbano. Ele vai assim ganhando existência a partir dessa ligação com o espaço, com o que está fora de seu corpo. Um modo de o corpo(r)existir e assim se significar.

Território Vermelho enquanto estrutura e acontecimento (PÊCHEUX, 1988) discursiviza corpos: o corpo curvado; o corpo que se 'fantasia' e se 'desfantasia'; o corpo... Pensando esse movimento entre o corpo e o seu fora no processo de identificação, Rolnik (2009, p.02) considera que:

[...]o dentro é uma desintensificação do movimento das forças do fora, cristalizadas temporariamente num determinado diagrama que ganha corpo numa figura com seu microcosmo; o fora é uma permanente agitação de forças que acaba desfazendo a dobra e seu dentro, diluindo a figura atual da subjetividade até que outra se perfile. Um tanto perplexos, nos damos conta que o dentro, aqui, nada mais é do que o interior de uma dobra da pele. E reciprocamente, a pele, por sua vez, nada mais é do que o fora do dentro.

Na dobra e por ela, na relação complexa, não mais agora de seu 'dentro' e 'fora', vão se constituindo traçados de um território de existência. Ao passo, que dentro e fora agora não tem mais a ver com meros espaços, "pelo contrário: o fora é uma nascente de linhas de tempo que se fazem ao sabor do acaso. Cada linha de tempo que se lança é uma dobra que se concretiza e se espacializa num território de existência, seu dentro" (ROLNIK, 2009, p.02).

Na relação tensa entre os jogos de luz/de sombra (câmera) e o sujeito, formulações deslizam e se distribuem na superfície da tela; acusando o silêncio de um braço estendido, de uma silhueta fletida nas latarias dos carros, monólogos em que o sujeito dito 'autônomo' transforma-se 'em senhor' de seu território. 
Câmera que recolhe os ruídos do mundo: as modificações de luz, o espaço fechado dos arranha-céus e dos carros e os trajetos possíveis por entre um território... Uma curta viagem em que a paisagem é vista e percorrida por seis corpos diferentes: corpos que produzem o sentido de 'para ver' mas que no trajeto próprio da imagem em que são capturados ficam embaraçados tanto para escapar aos nossos olhares; quanto para dar visibilidade à divisão sócio-histórica do espaço.

Formulações como "a câmera roda", "a câmera muda" e "a câmera dança" derivam, indo além, produzindo "seus efeitos de sentidos variados em que trabalha fortemente o silêncio. [...] sentidos pressionados, explosivos, manuseados com cautela" (ORLANDI, 2012, p. 19), mas que em suas partículas guardam uma parte ao silêncio. A câmera roda? Rodar (mera referência à cadeira de rodas) ou possibilidade outra de dizer sobre sujeitos e sentidos que também 'rodam' (?). A câmera muda? Mudar (câmera que se desloca por espaços físicos, percorre trajetos, vias) ou 'muda' (a que não fala pela sua própria impossibilidade, silenciada). Fuga de sentidos. A câmera dança? Dança (movimenta-se ao som do rap) ou dança com os sentidos?

A câmera;

Os sentidos;

E os sujeitos;

Qualquer um pode dançar.

Qualquer um pode rodar.

Sendo mudo ou ao se mudar.

Ponto de fuga que trabalha os desdobramentos de sentidos em diferentes formações discursivas que convivem no mesmo objeto simbólico.

Em cada acontecimento da palavra, em cada uma dessas formulações, se produz uma mexida na rede de filiações em suas diferentes condições específicas de produção. Ecos tecido por "muitas histórias, no plural", conforme aponta Orlandi (2012, p.20), "Fuga: porque, dada a ideologia uns ficam outros se vão. Historicidade. Matéria da contradição e do equívoco".

Jogando com as formulações, temos as imagens. E imagem, pensamos, não é repetição, é parte do acontecimento como já propôs Baudrillard (2003). Acontecimento da palavra e da imagem trabalhando com o sentido e o não-sentido; o 'dessignificado'/'insignificado' para Orlandi (2012).

Em mais uma volta no movimento da tela lemos: 
A câmera seduz

A câmera autônoma

A câmera clone

Palavras que falam. Na deriva o sujeito enuncia ou como neste caso, é enunciado. Fecha-se o plano, a tela fica escura e aos pedaços as formulações acima ganham espaço antes mesmo que o sujeito diga: eu sou. Esse é o trabalho da memória discursiva, do interdiscurso. Efeito da polissemia, da não-coincidência do sentido consigo mesmo, nem do sujeito em sua ordem do processo de significação e constituição. Então, sendo assim, questionamos como aí funciona a relação estreita da polissemia com o silêncio na predicação da câmera em Território Vermelho? A câmera é clone, ela seduz, é autônoma? Predicações/ 'palavras que falam e não falam com as outras'.

Surpresos, ficamos ao assistir novamente o documentário, pois pode-se acompanhar, que no interior desta dobra irrompem cenas que 'causam' o sujeito de todo um modo de 'enorme' e 'demorada' existência.

Mas isso compreendemos, afinal...

"O sertão é uma espera enorme"

(Graciliano Ramos)

\section{Referências}

BARBAI, Marcos Aurélio. Uma imagem na cidade: no flagrante um sentido. In. Caderno de Estudos Linguísticos, Campinas, 53(2):169-178, Jul./Dez. 2011

COSTA, Greciely Cristina. Linguagem em funcionamento: sujeito e criminalidade. Dissertação. Unicamp. 2008.

FEDATTO, Carolina Padilha, 1983- Um saber nas ruas: o discurso histórico sobre a cidade brasileira / Carolina Padilha Fedatto. -- Campinas, SP : [s.n.], 2011.

LAGAZZI-RODRIGUES, Suzy. Linha de Passe: a materialidade significante em análise. RUA [online]. 2010, no. 16. Volume 2 - ISSN 1413-2109.

O discurso em diferentes territórios: o vermelho entre todas as cores. Discurso, Sujeito, Memória, Campinas, SP: Pontes, 2012.

MARX, K. e ENGELS, F. O 18 Brumário e cartas a KugelmannI. 6 ed. Rio de Janeiro: Paz e Terra, 1997.

ORLANDI, Eni P. (1984). Segmentar ou Recortar. In: Série Estudos 10. Uberaba: FIU. A linguagem e seu funcionamento. São Paulo: Pontes, 1987. 
Discurso e leitura. São Paulo: Ed. UNICAMP: Cortez, 1988. cap.: Inteligibilidade, interpretação e compreensão.

Efeitos do verbal sobre o não-verbal. In.: Revista Rua. Campinas, S/ed. : março, $1995-\mathrm{n}^{\circ} .01$

(Org.). Gestos de leitura. Campinas: Ed. da UNICAMP, 1994a. 1994b.

Discurso, imaginário social e conhecimento. Brasília, ano 14, n.61, jan./mar. Vozes, 1996.

Interpretação: Autoria, leitura e efeitos do trabalho simbólico. Petrópolis-RJ

Do sujeito na história e no simbólico. In: Revista Escritos n⿳0 4: Contextos epistemológicos da análise do discurso. Campinas, SP: LABEURB, 1999.

. Análise de discurso: princípios e procedimentos. Campinas: Pontes, 1999.

. Discurso e Texto. Campinas. Pontes, 2001.

Cidade dos sentidos. Campinas/SP: Pontes, 2004.

Discurso em Análise: sujeito, sentido, ideologia. Campinas: Pontes, 2012.

A palavra dança e o mundo roda: Polícia!. In.: Cidade, Linguagem e Tecnologia:20 anos de História. Eduardo Guimarães. (Org.) Campinas/SP; LABEURB, 2013.

MALUF-SOUZA, Olímpia. Cidade, Discurso e Ideologia. Anais do Sead.[online]2010.http://www.discurso.ufrgs.br/anaisdosead/2SEAD/SIMPOSIOS/Oli mpiaMalufSouza.pdf.

MARIANI, Betânia (org.) A Escrita e os Escritos: reflexões em Análise do Discurso e Psicanálise. São Carlos: Editora Claraluz, 2006 (215-222)

PÊCHEUX, M.L'étrange miroir de l'Analyse Du Discours.In: Langages no 62, Paris, pp. 5-8; juin 1981. 1990 .

O discurso: estrutura ou acontecimento. Trad. Eni Orlandi. Campinas, SP: Pontes,

(1975) Semântica e Discurso: Uma Critica à Afirmação do Óbvio. Campinas, SP. Editora da UNICAMP. 2009.

(1978) Só há causa daquilo que falha ou o inverno político francês: início de uma retificação Em: Pêcheux, M. Semântica e discurso: uma crítica à afirmação do óbvio, Campinas: Ed. Unicamp, 1997.

Metáfora e Interdiscurso. In. Análise de Discurso Michel Pêcheux. Org. Eni P. Orlandi, Campinas, SP: Pontes Editores, 2011.

Papel da memória. In: ACHARD, Pierre et. al.. Papel da Memória. Campinas/SP: Pontes, 1999.

PÊCHEUX, M. e GADET, F (1981) A língua inatingível: o discurso na história da linguística. Campinas/SP: Pontes, 2004.

ROMÃO, Lucília Maria Souza. Sentidos de Clarice na exposição do Museu da Língua Portuguesa. Data Grama Zero - Revista de Ciência da Informação - v.10 n.1 fev08.

ROBIN, Régine. La mémoire saturée. Paris : Stock, 2003. 
ROLNIK, Sueli. Uma insólita viagem à subjetividade fronteiras com a ética e a cultura. 1997. Disponível em: http://caosmose.net/suelyrolnik/textos/sujeticabourdieu.doc Acesso em: 23jan. 2014

XAVIER, Ismail. O Discurso Cinematográfico: a opacidade e a transparência. Riode Janeiro: Paz e Terra, 1977.

ZOPPI-FONTANA, M. Cidadãos modernos. Campinas: Editora da Unicamp, 1997.

\section{Outras referências:}

GOIFMAN, Kiko. Território Vermelho [documentário-vídeo]. Produção de Jurandir Muller, direção de Kiko Goifman, São Paulo, 2004.

Data de Recebimento: 19/02/2016

Data de Aprovação: 07/06/2016 


\section{Para citar essa obra:}

SALLES, A. C. COSTA, G. Recortes e(m) análise: no movimento da narratividade cinematográfica. In: RUA [online]. $\mathrm{n}^{\circ} .22$. Volume 2, p. 553 - 572 - ISSN 14132109/2179-9911 - Junho/2016. Consultada no Portal Labeurb - Revista do Laboratório de Estudos Urbanos do Núcleo de Desenvolvimento da Criatividade. http://www.labeurb.unicamp.br/rua/

Laboratório de Estudos Urbanos - LABEURB

Núcleo de Desenvolvimento da Criatividade - NUDECRI

Universidade Estadual de Campinas - UNICAMP

http://www.labeurb.unicamp.br/

\section{Endereço:}

LABEURB - LABORATÓRIO DE ESTUDOS URBANOS

UNICAMP/COCEN / NUDECRI

CAIXA POSTAL 6166

Campinas/SP - Brasil

CEP 13083-892

Fone/ Fax: (19) 3521-7900

Contato: http://www.labeurb.unicamp.br/contato 